\title{
Correlation between superficial and intra-operative specimens in diabetic foot infections: results of a cross-sectional Tunisian study
}

\author{
Foued Bellazreg ${ }^{1}$, Ahmed Guigua ${ }^{2}$, Asma Ferjani ${ }^{3}$, Zouhour Hattab ${ }^{1}$, Jalel Boukadida ${ }^{3}$, \\ Koussay Ach ${ }^{4}$, Rached Letaief ${ }^{5}$, Wissem Hachfi ${ }^{1}$, Amel Letaief ${ }^{1}$
}

1. Department of Infectious Diseases, Farhat Hached hospital, 4000 Sousse, Tunisia.

2. Department of Internal Medicine, Farhat Hached hospital, 4000 Sousse, Tunisia.

3. Department of Microbiology, Farhat Hached hospital, 4000 Sousse, Tunisia.

4. Department of Endocrinolgy, Farhat Hached hospital, 4000 Sousse, Tunisia.

5. Department of General Surgery, Farhat Hached hospital, 4000 Sousse, Tunisia.

\section{Email addresses:}

Ahmed Guigua : guiguaahmad@gmail.com; Asma Ferjani : aferjani76@gmail.com; Zouhour Hattab : zouhourhattab@yahoo. fr; Jalel Boukadida : jalel.boukadida@rns.tn; Koussay Ach : koussay.ach@rns.tn; Rached Letaief : rached.letaief@rns.tn; Wissem Hachfi : wissemhachfi@gmail.com; Amel Letaief : ameletaief@gmail.com

\begin{abstract}
:
Objective: To determine the correlation between superficial, and intra-operative specimens in diabetic foot infections (DFIs). Methods: We conducted a cross-sectional study in patients with DFIs hospitalized in a Tunisian teaching hospital. Superficial specimens were collected for all patients, and intra-operative specimens were collected in operated patients. The specimens were processed using standard microbiology techniques. Antimicrobial susceptibility testing was carried out according to the protocol established by the European Committee on Anti-microbial Susceptibility Testing. Intra-operative and superficial specimens were considered correlated if they isolated the same microorganism(s), or if they were both negative.

Results: One hundred twelve patients, 81 males and 31 females, mean age 56 years, were included. Superficial samples were positive in $77 \%$ of cases, and isolated 126 microorganisms. Among the positive samples, $71 \%$ were monomicrobial. The most frequently isolated microorganisms were Enterobacteriaceae (53\%), followed by streptococci (21\%) and Staphylococcus aureus (17\%). Nine microorganisms $(7 \%)$ were multi-drug resistant. Intra-operative samples were positive in 93\% of cases. Superficial specimens were correlated to intra-operative specimens in $67 \%$ of cases. Initial antibiotic therapy was appropriate in $70 \%$ of cases. The lower-extremity amputation and the mortality rates were $41 \%$ and $1 \%$, respectively.

Conclusion: In our study, DFIs were most frequently caused by Enterobacteriaceae and superficial specimens were correlated to intra-operative specimens in only two thirds of cases. Clinicians should emphasize on the systematic practice of intraoperative specimens in all patients with DFIs treated surgically, while well-performed superficial specimens could be useful for prescribing appropriate antibiotic therapy in other patients.
\end{abstract}

Keywords: Diabetic foot infections, superficial specimens, intra-operative specimens.

DOI: https://dx.doi.org/10.4314/ahs.v19i3.26

Cite as: Bellazreg F, Guigua A, Ferjani A, Hattab Z, Boukadida J, Ach K, Letaief R, Hachfi W, Letaief A. Correlation between superficial and intra-operative specimens in diabetic foot infections: results of a cross-sectional Tunisian study. Afri Health Sci. 2019;19(3): $2505-2514$. bttps:/ / dx.doi.org/10.4314/abs.v19i3.26

\section{Corresponding author: \\ Foued Bellazreg, \\ Department of Infectious Diseases, \\ Farhat Hached hospital, 4000 Sousse, Tunisia \\ Telephone : 0021673102556 \\ Fax: 0021673102516 \\ Email: fouedbellazreg@yahoo.fr}

\section{Introduction}

Diabetic foot infections (DFIs) are common and serious. They occur in $15-25 \%$ of diabetic patients in the course of their disease, and are associated with high rates of lower extremity amputation (LEA) and mortality. The annual incidence of LEA ranges from 3.6\% in Germany to $6.7 \%$ in France and $12 \%$ in India, and the annual mortality ranges from $7.8 \%$ in France to $9.6 \%$ in Scotland ${ }^{1-5}$.

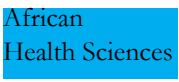

C 2019 Bellazreg et al. Licensee African Health Sciences. This is an Open Access article distributed under the terms of the Creative commons Attribution License (https://creativecommons.org/licenses/BY/4.0), which permits unrestricted use, distribution, and reproduction in any medium, provided the original work is properly cited. 
The average direct cost for LEA ranges from $€ 19472$ per patient in Germany, to $\$ 33500$ per patient in the $\mathrm{USA}^{6,7}$. In Tunisia, the prevalence of type 2 diabetes mellitus in adults is as high as $10.9 \%{ }^{8}$.

In addition to surgical procedures, podiatric care and arterial re-vascularization, antibiotic therapy is the corner stone in the management of DFIs. For most patients, initial antibiotic therapy is empirical, hence the need for local bacteriological data. To the best of our knowledge, only two studies reported bacteriological profile in DFIs in Tunisia ${ }^{9,10}$. Furthermore, most bacteriological studies in DFIs were based on superficial specimens, using cotton swab over the wound, often contaminated with normal skin flora or colonizers. Swab specimens should be avoided as they provide less accurate results ${ }^{11}$. The aim of this study was to determine the bacteriological profile, and the correlation between superficial and intra-operative specimens in DFIs in a Tunisian tertiary hospital.

\section{Methods}

\section{Study design and population}

We conducted an observational cross-sectional study in adult patients hospitalized for DFIs in the Departments of Infectious Diseases, General Surgery and Endocrinology, at Farhat Hached hospital in Sousse - Central Tunisia, between October 2011 and December 2012.

DFIs were defined by the presence of purulent secretions or at least two of the following signs: pain, redness, warmth, swelling, and fever. They were graded according to the Infectious Diseases Society of America/International Working Group on the Diabetic Foot (IDSA/IWGDF) system ${ }^{12,13}$. Socio-demographic, clinical, and bacteriological data was collected for each patient. Antibiotic therapy was considered appropriate if the microorganisms isolated from superficial and intra-operative specimens were susceptible to the prescribed antibiotics. The patients' outcome was assessed within one month after discharge.

\section{Specimens' collection and bacteriological study}

On admission, superficial specimens were collected for all patients. Swabs after debridement and cleansing with saline imbibed sterile compress were taken for open wounds, and needle aspirates after cleansing with polyvidone-iodin solution were taken for closed lesions (abscesses and other fluctuant infected tissues). In operated patients, intra-operative specimens were obtained by pus needle aspirates, infected soft tissues biopsies, or bone biopsies, in case of osteomyelitis. All specimens were sent within one to two hours to the laboratory of Microbiology in our hospital ${ }^{14,15}$.

The specimens were transported in sterile tubes without transport medium, and were processed immediately upon arrival at the laboratory. Superficial specimens were immediately plated onto blood agar and supplemented chocolate agar. Intra-operative specimens were cut, crushed, and plated systematically on the same agars as above, added to thioglycolate medium, and Brain Heart Infusion (BHI). A direct Gram stained smear of the specimen was examined.

The inoculated plates were incubated at $37^{\circ} \mathrm{C}$ overnight, and the plates were examined for growth, the next day. The further processing was done according to the nature of the isolate, as was determined by Gram staining and the colony morphology. Based on Gram-staining and colony morphology, bacterial isolates were identified, and biochemical reactions were performed for confirmation Api systems (bioMérieux, Marcy l'Etoile, France). Species which were considered systematically as pathogens spp were: Staphylococcus aureus, beta hemolytic Streptococcus and Gram negative bacilli (GNB). Commensal bacteria were taken into account, if they were isolated in pure culture on repeated and good quality samples by taking into account the direct Gram stained.

All isolated strains which were considered as pathogens were subjected to susceptibility testing against antimicrobial agents by the disk diffusion method, according to the European Committee on Antimicrobial Susceptibility Testing (EUCAST) protocols. The following multidrug resistant (MDR) organisms were screened as recommended: extended-spectrum beta lactamases (ESBL)-producing Enterobacteriaceae, carbapenemase-producing Enterobacteriaceae, MDR Pseudomonas aeruginosa, meticillin-resistant Staphylococcus aureus (MRSA), and vancomycin-resistant Enterococcus (VRE). The following risk factors for infection with MDR bacteria were screened : hospitalization, antibiotic therapy, proton pump inhibitors use, or urinary catheter in the preceding six months, and current hemodialysis.

\section{Correlation between superficial and intra-operative specimens}

Intra-operative and superficial specimens were considered correlated if they isolated the same microorganism(s) or if they were both negative, and not correlated if they iso- 
lated different microorganisms or if one specimen was positive and the other negative.

\section{Statistical study}

Statistical analysis was performed with Statistical Package for Social Sciences (SPSS) version 10.0. Qualitative variables were expressed as percentages, and quantitative variables were expressed as means \pm standard deviation. Significance of the study variables was tested by using the Chi-square test, Fisher's exact test, or Yates test for qualitative variables, and Student's t-test for quantitative variables. A p value $<0.05$ was considered to be statistically significant.

\section{Ethical considerations}

As our study didn't involve changes to the patients' usual medical management, no study protocol had been submitted to our hospital Ethics Committee approval. However, patients were provided with oral information on the interest of the bacteriological documentation of the infection, and gave their verbal consent before being included in the study.

\section{Results}

\section{Baseline characteristics}

During the study period, 112 patients were hospitalized for DFI. Of these patients, $81(72 \%)$ were male and 31
$(28 \%)$ were female (sex-ratio 2.3). The mean age of the patients was 56 years, the mean duration of diabetes was 14 years, and the mean A1c hemoglobin (HbA1c) level was $11.5 \%$. The mean duration of the infection was 10 days. The infection involved the toes in 47 cases (42\%) and the forefoot in 46 cases $(41 \%)$. Fourty eight patients $(43 \%)$ had grade 4 infection, $45(40 \%)$ had grade 3 infection, and $19(17 \%)$ had grade 2 infection. Twenty two patients $(20 \%)$ had a history of anti-biotic treatment within the previous 7 days. A total of 17 intravenous antibiotic regimens were prescribed, on the day of admission to hospital in 106 patients (95\%) and after the results of the bacteriological study in 6 patients $(5 \%)$. Monotherapy with amoxicillin-clavulanic acid (55/106; 52\%) and the combination amoxicillin-clavulanic acid with ciprofloxa$\operatorname{cin}(25 / 106 ; 24 \%)$ were the most frequently prescribed antibiotics. The initial antibiotic therapy, assessed in the 87 patients, whose bacteriological specimens were positive, was appropriate in 61 cases $(70 \%)$. Seventy four patients $(66 \%)$ underwent surgery. LEA was performed in 46 patients (41\%), while conservative surgery was performed in 28 patients $(25 \%)$. Amputation was limited to the toes in 32 patients $(28 \%)$, and transmetatarsal in one patient $(1 \%)$, while leg amputation was performed in 13 patients $(12 \%)$. One patient $(1 \%)$ died of severe acute lung edema. The baseline characteristics are shown in Table 1 . 
Table 1. Baseline characteristics of the study group $(\mathrm{N}=112)$

\begin{tabular}{|c|c|c|}
\hline Parameters & Patients $(\mathrm{n}, \%)$ & Mean $( \pm \mathrm{SD})$ [range] \\
\hline $\begin{array}{l}\text { Gender } \\
\text { male } \\
\text { female }\end{array}$ & $\begin{array}{l}81(72) \\
31(28)\end{array}$ & \\
\hline Age (years) & & $56 \pm 13[23-86]$ \\
\hline $\begin{array}{l}\text { Department } \\
\text { Infectious Diseases } \\
\text { General Surgery } \\
\text { Endocrinology }\end{array}$ & $\begin{array}{l}73(65) \\
25(22) \\
14(12)\end{array}$ & \\
\hline $\begin{array}{l}\text { Diabetes mellitus } \\
\text { type } 2 \\
\text { type } 1 \\
\text { duration (years) } \\
\mathrm{Hb} \text { A1c }(\%)\end{array}$ & $\begin{array}{l}92(82) \\
20(18)\end{array}$ & $\begin{array}{c}14 \pm 9[0-42] \\
11.5 \pm 2.2[7.2-16]\end{array}$ \\
\hline $\begin{array}{l}\text { Cardiovascular risk factors } \\
\text { tobacco use } \\
\text { hypertension } \\
\text { dyslipidemia }\end{array}$ & $\begin{array}{l}47(42) \\
36(32) \\
24(20)\end{array}$ & \\
\hline $\begin{array}{l}\text { Foot infection site } \\
\text { toes } \\
\text { forefoot } \\
\text { heel }\end{array}$ & $\begin{array}{l}47(42) \\
46(41) \\
19(17)\end{array}$ & \\
\hline $\begin{array}{l}\text { Foot infection grade } \\
\text { grade } 4 \\
\text { grade } 3 \\
\text { grade } 2\end{array}$ & $\begin{array}{l}48(43) \\
45(40) \\
19(17)\end{array}$ & \\
\hline Foot infection duration & & $10 \pm 9[1-60]$ \\
\hline $\begin{array}{l}\text { Antibiotic regimens } \\
\text { AMC* } \\
\text { AMC }+ \text { ciprofloxacin } \\
\text { others }\end{array}$ & $\begin{array}{l}55(52) \\
25(24) \\
26(24)\end{array}$ & \\
\hline $\begin{array}{l}\text { Surgery } \\
\text { lower extremity amputation } \\
\quad \text { toes } \\
\quad \text { transmetatarsal } \\
\quad \text { leg } \\
\text { Conservative }\end{array}$ & $\begin{array}{l}74(66) \\
46(41) \\
32(28) \\
1(1) \\
13(12) \\
28(25)\end{array}$ & \\
\hline Death & $1(1)$ & \\
\hline
\end{tabular}

\section{Bacteriological study \\ Superficial specimens}

Initial superficial specimens, taken in 112 patients, mostly by swabs (110 cases, $98 \%$ ), yielded a positive culture in 86 cases $(77 \%)$. Antibiotic therapy prior to hospitalization was noted in $17 \%(15 / 86)$ of patients with positive culture, and in $27 \%(7 / 26)$ of patients with negative culture $(p=0.18)$. In 11 patients with negative initial specimen, a second specimen was performed. Culture was positive in 7 cases. Overall, 93 superficial specimens (/112 patients, $83 \%$ ) were positive and isolated 126 micro-organisms (Figure 1). The mean number of isolates per specimen was 1.35 (range, 1-3). One micro-organism was isolated in 66 cases $(71 \%), 2$ micro-organisms were isolated in 21 cases $(23 \%)$, and 3 micro-organisms were isolated in 6 cases $(6 \%)$. The most frequently isolated micro-organisms were GNB (60\%), mainly Enterobacteriaceae (53\%), followed by Gram positive bacteria (40\%), mainly Streptococci $(21 \%)$ and Staphylococcus aureus (17\%). The predominance of GNB was observed, regardless the duration of infection: $\leq 7$ days $(57 \%)$ compared to $>7$ days $(64 \%)$ $(\mathrm{p}=0.15)$, and $\leq 15$ days $(68 \%)$ compared to $>15$ days $(50 \%)(\mathrm{p}=0.96)$. A predominance of GNB (69\%) compared to Gram positive bacteria $(31 \%)(p=0.004)$ was 
noted in grade 2 and grade 3 infections, while no significant difference ( $46 \%$ and $54 \%$ respectively, $\mathrm{p}=0.056)$ was noted in grade 4 infections. The antibiotic susceptibility rates of isolated micro-organisms were as follows: piperacillin-tazobactam (99\%), imipenem (98\%), cefotaxime (93\%), ertapenem $(93 \%)$, amoxicilline-clavulanic acid $(87 \%)$, cotrimoxazole $(86 \%)$, ciprofloxacin $(58 \%)$. Nine micro-organisms $(7 \%)$, including $8 \mathrm{GNB}(/ 75,11 \%)$ and one meticillin-resistant Staphylococcus aureus (MRSA) (/22, 4\%), were multidrug resistant (MDR). The risk factors of infection with a MDR bacteria were hospitalization in the preceding six months ( 7 patients), antibiotic therapy in the preceding six months (5 patients), proton pump inhibitors use in the preceding six months ( 3 patients), and urinary catheter in the preceding six months (2 patients). The bacteriological data of the superficial specimens are summarized in Table 2 and Table 3.

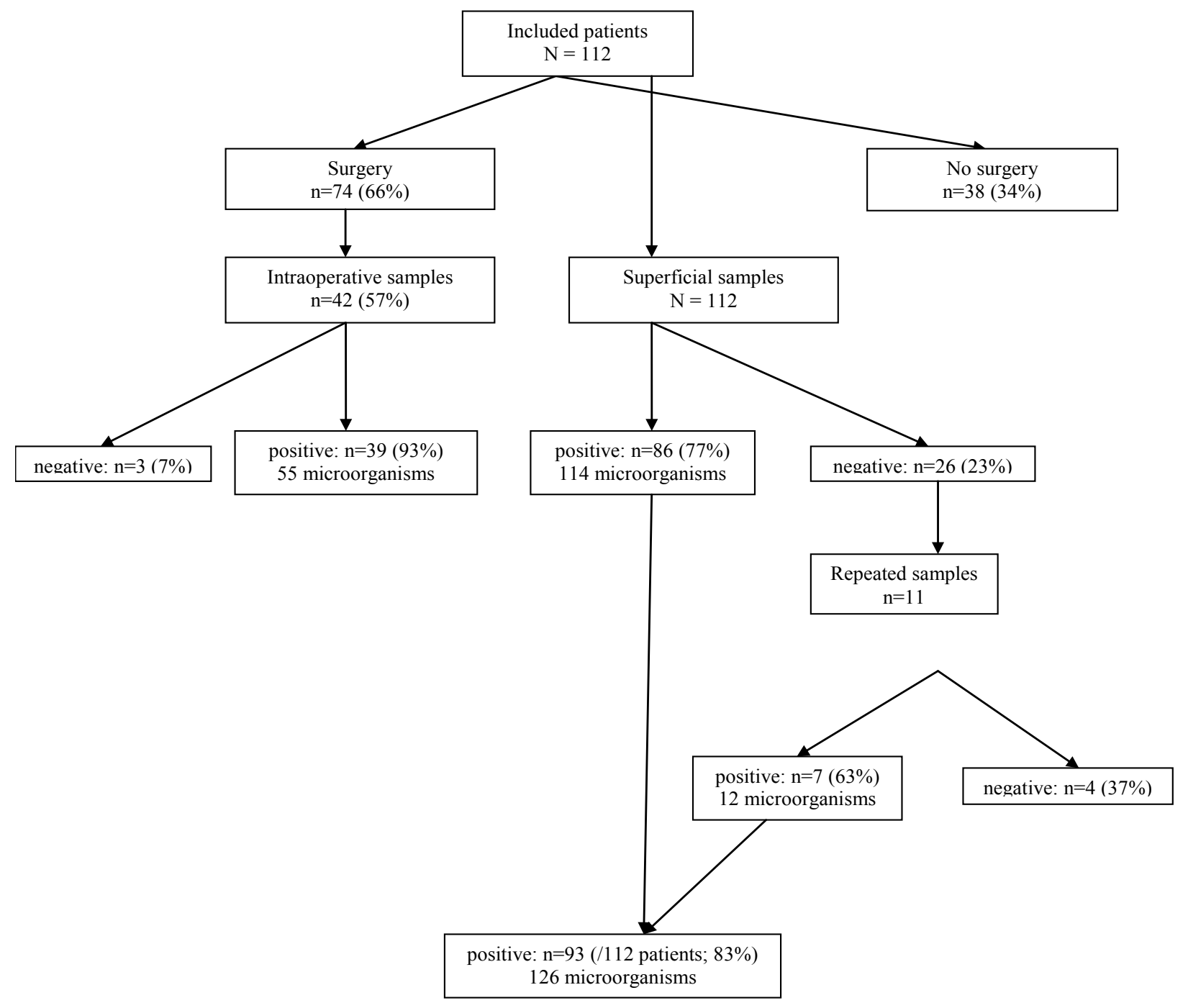

Figure 1. Bacteriological study of superficial and intraoperative specimens 
Table 2. Distribution of microorganisms obtained from superficial and intra-operative specimens

\begin{tabular}{|c|c|c|c|}
\hline Variable & $\begin{array}{l}\text { superficial specimens } \\
(\mathrm{n}, \%)\end{array}$ & $\begin{array}{c}\text { Intra-operative specimens } \\
(\mathrm{n}, \%)\end{array}$ & $\mathrm{p}$ \\
\hline No. of samples & 93 & 42 & \\
\hline No. of isolates & 126 & 55 & \\
\hline Mean no. of isolates per sample & 1.35 & 1.41 & 0.32 \\
\hline Monomicrobial & $66(71)$ & $25(64)$ & 0.55 \\
\hline Multidrug resistant & $9(7)$ & 5 (9) & 0.37 \\
\hline Gram negative aerobic bacilli & $75(60)$ & $37(67)$ & 0.97 \\
\hline Enterobacteriaceae & $67(53)$ & $32(58)$ & 0.38 \\
\hline Proteus spp & $22(17)$ & $9(16)$ & \\
\hline Klebsiella spp & $11(10)$ & 7 (13) & \\
\hline Morganella morganii & $9(7)$ & $5(9)$ & \\
\hline Citrobacter spp & $8(6)$ & $5(9)$ & \\
\hline Enterobacter cloacae & $8(6)$ & $4(7)$ & \\
\hline others & $9(7)$ & $2(4)$ & 0.5 \\
\hline Pseudomonas aeruginosa & $8(6)$ & $5(9)$ & \\
\hline Gram positive cocci & $48(38)$ & $16(29)$ & 0.31 \\
\hline Streptococci & $26(21)$ & $9(16)$ & 0.5 \\
\hline group B & $15(12)$ & $6(11)$ & \\
\hline group $\mathrm{A}$ & $8(7)$ & $1(2)$ & \\
\hline others & $3(2)$ & $2(3)$ & \\
\hline Staphylococcus aureus & $22(17)$ & $7(13)$ & 0.34 \\
\hline Gram positive aerobic bacilli & $3(2)$ & $2(3)$ & \\
\hline Corynebactrium spp & $3(2)$ & $2(3)$ & \\
\hline
\end{tabular}

Table 3. Susceptibility of isolated microorganisms to antibiotics

\begin{tabular}{|c|c|c|c|}
\hline Antibiotic & $\begin{array}{c}\text { superficial samples }(\mathrm{N}=126) \\
\text { susceptible }(\mathrm{n}, \%)\end{array}$ & $\begin{array}{c}\text { intraoperative samples }(\mathrm{N}=55) \\
\text { susceptible }(\mathrm{n}, \%)\end{array}$ & $\mathrm{p}$ \\
\hline amoxicillin-clavulanic acid & $110(87)$ & $47(85)$ & 0.72 \\
\hline cefotaxime & $117(93)$ & $50(91)$ & 0.61 \\
\hline piperacillin-tazobactam & 125 (99) & $55(100)$ & NA \\
\hline ertapenem & $118(93)$ & $51(93)$ & 0.55 \\
\hline imipenem & $123(98)$ & $53(96)$ & 0.50 \\
\hline amikacin & $116(92)$ & $51(93)$ & 0.82 \\
\hline gentamicin & $112(89)$ & $49(89)$ & 0.67 \\
\hline ciprofloxacin & $67(58)$ & $39(70)$ & 0,07 \\
\hline cotrimoxazole & $109(86)$ & $50(91)$ & 0.34 \\
\hline fosfomycin & $116(92)$ & $54(98)$ & 0.21 \\
\hline vancomycin & $48(38)$ & $16(29)$ & 0.09 \\
\hline pristinamycin & $47(37)$ & $19(34)$ & 0.56 \\
\hline fusidic acid & $19(15)$ & $6(10)$ & 0.52 \\
\hline rifampicin & $44(39)$ & $15(27)$ & 0.21 \\
\hline
\end{tabular}

\section{Intra-operative specimens}

Intraoperative specimens, taken in 42 patients (among 74 operated, ie $57 \%$ ), were positive in 39 cases (93\%) and isolated 55 micro-organisms. The mean number of isolates per sample was 1.41 (range,1-3). One micro-organism was isolated in 25 cases (64\%), 2 micro-organisms were isolated in 12 cases $(31 \%)$, and 3 micro-organisms were isolated in 2 cases $(5 \%)$. The most frequently isolated microorganisms were GNB (67\%), mainly Enterobacteriaceae (58\%), followed by Gram positive bacteria (29\%), mainly Streptococci (16\%) and Staphylococcus aureus (13\%). A predominance of GNB (78\%), compared to Gram positive bacteria $(22 \%)(p=0.002)$ was noted in grade 2 and grade 3 infections, while no significant difference (48\% and $52 \%$ respectively, $\mathrm{p}=0.09$ ) was noted in grade 4 infections. The antibiotic susceptibility rates of isolated mi- croorganisms were as follows: piperacillin-tazobactam $(100 \%)$, imipenem $(96 \%)$, cefotaxime $(91 \%)$, ertapenem (93\%), amoxicilline-clavulanic acid (85\%), cotrimoxazole (91\%), ciprofloxacin (70\%). Five microorganisms (9\%), including $3 \mathrm{GNB}(/ 37 ; 8 \%)$ and $2 \mathrm{MRSA}(/ 7 ; 29 \%)$, were MDR. The bacteriological data of the intraoperative specimens are summarized in Table 2 and Table 3.

\section{Correlation between superficial and intraoperative specimens}

A correlation between intra-operative and superficial specimens was noted in 28 cases $(67 \%)$. This rate was higher for GNB (78\%), than for Gram positive cocci $(50 \%)(p=0.27)$ (Table 4). There was no significant difference in the bacteriological profile, and in the antibiotic susceptibility rates between superficial, and intra-operative specimens (Table 2 and Table 3 ). 
Table 4. Correlation rates between superficial and intraoperative specimens

\begin{tabular}{|c|c|c|}
\hline $\begin{array}{l}\text { Microorganisms isolated } \\
\text { from intraoperative specimens }\end{array}$ & number of specimens (\%) & correlation rate (\%) \\
\hline Gram negative aerobic bacilli & 23 & 78 \\
\hline Proteus spp & 5 & \\
\hline Klebsiella spp & 4 & \\
\hline Morganella morganii & 4 & \\
\hline Citrobacter koseri & 3 & \\
\hline others & 7 & \\
\hline Gram positive cocci & 12 & 50 \\
\hline Streptococci & 4 & \\
\hline Staphylococcus aureus & 3 & \\
\hline others & 5 & \\
\hline Others & 7 & 57 \\
\hline mixed flora & 3 & \\
\hline Corynebacterium spp & 1 & \\
\hline negative & 3 & \\
\hline Total & $42(100)$ & 67 \\
\hline
\end{tabular}

\section{Discussion}

In our study, both superficial and intra-operative specimens were frequently positive $(77 \%$ and $93 \%$, respectively), even in patients who received antibiotics within the previous days. Most bacteriological samples were monomicrobial $(71 \%)$, and the most frequently isolated micro-organisms were GNB (60\%), mainly Enterobacteriacae (53\%), followed by Gram positive cocci (38\%) mainly streptococci (21\%), while Staphylococcus aureus was less frequently isolated $(17 \%)$. The predominance of GNB was noted, regardless of the duration of infection. In our study, no anaerobe was isolated. Indeed, the majority of cultures were performed from superficial specimens, and both transportation media, and culture conditions for anaerobes are not available in the laboratory of Microbiology in our hospital.
In published series, the pre-dominance of mono-microbial or poly-microbial specimens and the distribution of isolated micro-organisms varied considerably. Gram positive cocci were most frequently (52.6 to 68\%) isolated in some studies, while GNB were most frequently (56 to 80\%) in others 10, 16-22]. In a Turkish study, Gram positive cocci $(48.7 \%)$ and GNB (48.4\%) were isolated at an equal frequency ${ }^{23}$. Among the Gram positive cocci, the most commonly isolated micro-organism was Staphylococcus aureus, followed by Streptococci and enterococci, while among the GNB, the most commonly isolated micro-organisms were the Enterobacteriacea (mainly Proteus spp, Klebisella spp, and Escherichia coli) and Pseudomonas aeruginosa ${ }^{16-23}$. Despite anaerobes were frequently (13.6 to $25 \%$ ) isolated from DFIs in some studies, these microorganisms were not or rarely $(0.3$ to $2 \%)$ isolated in most other studies ${ }^{10,16,17,19-22 \text {, }}$ 24-26. This may be attributed to the difficulty in ensuring adequate sampling, transportation, and culture conditions for these fastidious pathogens. The bacteriological data of different studies are shown in Table 5. 
Table 5. Distribution of the microorganisms isolated from diabetic foot infections in different studies

\begin{tabular}{|c|c|c|c|c|c|c|c|}
\hline Variable & Our study & $\begin{array}{c}\text { Ben Moussa et al. } \\
\text { Tunisia [10] }\end{array}$ & $\begin{array}{c}\text { Richard et al. } \\
\text { France [16] }\end{array}$ & $\begin{array}{c}\text { Tascini et al. } \\
\text { Italy [17] }\end{array}$ & $\begin{array}{l}\text { Hatipoglu et al. } \\
\text { Turkey [23] }\end{array}$ & $\begin{array}{c}\text { Sekhar et al. } \\
\text { India [22] } \\
\end{array}$ & $\begin{array}{l}\text { Perim et al. } \\
\text { Brazil [19] }\end{array}$ \\
\hline Study period & $2011-12$ & $2011-13$ & $2007-09$ & $2006-08$ & $1989-2011$ & 2011 & 2013 \\
\hline Number of patients & 112 & 100 & 291 & 1295 & 2097 & 108 & 41 \\
\hline Number of samples & 93 & 124 & 251 & 1295 & - & 108 & 41 \\
\hline Number of isolates & 126 & 136 & 351 & 1159 & 1974 & 150 & 89 \\
\hline Mean No. of isolates per & 1.35 & 1.1 & 1.4 & 0.9 & - & 1.39 & 2.17 \\
\hline sample Monomicrobial (\%) & 71 & 55 & 68 & 60.5 & - & 44 & 30 \\
\hline Gram negative aerobic bacilli(\%) & 60 & 80 & 35.9 & 40.6 & 48.4 & 56 & 31 \\
\hline Enterobacteriaceae & 53 & 71 & 27,1 & 23.5 & 28.5 & 28 & 26.5 \\
\hline Proteus spp & 17 & 27 & 8.5 & - & 5.3 & 8 & 11 \\
\hline Klebsiella spp & 10 & 17 & 1.1 & - & 6.5 & 12 & 0 \\
\hline Morganella spp & 7 & 0 & 4.3 & - & - & 0 & 0 \\
\hline Citrobacter spp & 6 & 3 & 1.1 & - & - & 0 & 1.0 \\
\hline Enterobacter spp & 6 & 6 & 4.8 & - & 4.0 & 0 & 10 \\
\hline Serratia spp & - & 3 & 1.4 & - & - & 0 & 0 \\
\hline Escherichia coli & - & 7 & 4.8 & - & 12.5 & 8 & 4.5 \\
\hline Others & 7 & 6 & 0.9 & - & - & 0 & 0 \\
\hline Pseudomonas aeruginosa & 6 & 8 & 6.6 & 10.3 & 13.7 & 24 & 4.5 \\
\hline Acintetobacte spp & 0 & 1 & 0.9 & 1 & 1.9 & 4 & 0 \\
\hline Other Gram negative aerobic bacilli & 0 & 0 & 1.4 & 2 & 4.6 & 0 & 0 \\
\hline Gram positive cocci (\%) & 38 & 19 & 59.8 & 52.6 & 48.7 & 44 & 68 \\
\hline Staphylococcus aureus & 17 & 9 & 32.5 & 29.9 & 23.8 & 32 & 30 \\
\hline Coagulase-negative Staphylococci & 0 & 0 & 4.6 & 4.6 & 8.9 & 0 & 29 \\
\hline Streptococci & 21 & 10 & 13.7 & 4.6 & 6.5 & 4 & 9 \\
\hline group B & 12 & 5 & - & 2.8 & - & - & 7 \\
\hline groupe $\mathrm{A}$ & 7 & 0 & - & - & - & - & 0 \\
\hline others & 2 & 5 & - & 1.8 & - & - & 2 \\
\hline Enterococci & 0 & 0 & 8.0 & 9.7 & 8.6 & 8 & 0 \\
\hline Others & 0 & 0 & - & - & 1.0 & - & 0 \\
\hline Gram positive aerobic bacilli (\%) & 2 & 0 & 2.3 & 3.5 & - & 0 & 0 \\
\hline Corynebactrium spp & 2 & 0 & 2.3 & 3.5 & - & 0 & 0 \\
\hline Anaerobes (\%) & 0 & 0 & 2 & 0.3 & 2.3 & 0 & 0 \\
\hline Fungus $(\%)$ & 0 & 0 & 0 & $6.4^{*}$ & 0.5 & 0 & 0 \\
\hline
\end{tabular}

- : not available ; * all of Candida genus

The differences in DFIs bacteriological profile noted between the different studies may be explained by many factors such as the duration and the severity of the infection, prior antibiotic therapy, hospital or out-patient care, bacteriological sampling (superficial swabbing, needle puncture, bone percutaneous biopsy, intra-operative pus swabbing or tissue biopsy), and bacteriological study (transportation medium and culture conditions).

In our study, a correlation between superficial and intraoperative specimens was noted in only $67 \%$ of cases, with no significant difference between GNB, Gram positive cocci or mixed isolates. In two other studies, the overall correlation rate was as low as $50 \%$, between superficial swabs and deep tissue percutaneous biopsy, and 62\% between superficial swabs and deep tissue surgical biop$\mathrm{sy}^{27,28}$. Intra-operative specimens are more reliable and must be performed whenever possible, even in patients undergoing anti-biotic therapy. However, in our study, intra-operative specimens were performed in only $57 \%$ of cases. Thus, in daily practice, superficial specimens could provide useful information to guide antibiotic therapy in patients with DFIs.

In the present study, 17 antibiotic regimens were prescribed as first-line therapy, $66 \%$ of them were appropriate. The most frequently prescribed regimens were amoxicillin-clavulanic acid (52\%) and the association of amoxicillin-clavulanic acid with ciprofloxacine (24\%). In a Tunisian study, initial antibiotic therapy was appropriate in only $56 \%$ of cases, and in a French study, 62 combinations of antibiotics were prescribed as first-line therapy, of whom $56 \%$ were changed, mainly due to a mismatch in susceptibility results ${ }^{10,16}$. These high rates of inappropriate initial antibiotic therapy may be explained by the lack of local bacteriological data, to guide initial antibiotic therapy in DFIs. In our study, the initial antibiotic therapy was empirical in almost all cases (95\%), because the DFIs was frequently serious (grade 3 or grade 4 in $83 \%$ of cases) on admission. This may be explained by the long dura- 
tion of diabetes, the poor glycemic control, the frequent association of cardiovascular risk factors, and the delay in consultation.

In this study, the overall antibiotic susceptibility rates of the isolated microorganisms were high $(87 \%$ for amoxicillin-clavulanic acid, 86\% for cotrimoxazole, 99\% for piperacillin-tazobactam, and $92 \%$ for amikacin) except for fluoroquinolones (58\%), and the rates of infection with MDR microorganisms were low both for GNB (11\%) and Staphylococcus aureus (4.5\%). In other studies, the rates of infection with MDR microorganisms ranged from 9.5\% in Tunisia to $12 \%$ in France and $18.9 \%$ in Portugal. ${ }^{10,16,20}$ According to these data, we could recommend as first-line antibiotic therapy for DFIs in our setting either amoxicillin-clavulanic acid or cotrimoxazole in patients without severe sepsis, and the association of piperacillin-tazobactam with amikacin in patients with severe sepsis or septic shock. Fluoroquinolones could be prescribed only after the isolation of a susceptible microorganism from bacteriological sample, especially in patients with osteomyelitis. However, since this study was conducted 5 years ago, the bacteriological resistance may have evolved. Thus, further studies are needed to establish more recent bacteriological data in DFIs in our setting.

This study has potential limitations since some data such as clinical outcome, interval between patient admission and surgical treatment, antibiotic treatment duration and revascularization procedures were not available.

\section{Conclusion}

In the present study, DFIs were most commonly caused by GNB, mainly Enterobacteriaceae, regardless the duration of the infection. The isolated microorganisms were frequently susceptible to first-line prescribed antibiotics, except for fluoroquinolones. Superficial and especially intra-operative samples yielded positive cultures in the majority of cases, even in patients who received antibiotics within the previous few days, and the correlation rate between the two sampling techniques was low. In conclusion, clinicians should emphasize on the systematic practice of intra-operative specimens in all patients with DFIs treated surgically, while well-performed superficial specimens could be useful for prescribing appropriate antibiotic therapy in other patients.

\section{Conflicts of interest}

None.

\section{References}

1. International Working Group on the Diabetic Foot. Epidemiology of diabetic foot infections in a population-based cohort. Paper presented at: International Consensus on the Diabetic Foot; May 22-24,2003; Noordwijkerhout, the Netherlands.

2. Lavery LA, Armstrong DG, Wunderlich RP, Tredwell J, Boulton AJ. Diabetic foot syndrome: evaluating the prevalence and incidence of foot pathology in Mexican Americans and non-Hispanic whites from a diabetes disease management cohort. Diabetes Care. 2003;26:1435-8 PubMed .

3. Pscherer S, Dippel FW, Lauterbach S, Kostev K. Amputation rate and risk factors in type 2 patients with diabetic foot syndrome under real-life conditions in Germany. Prim Care Diabetes. 2012;6(3):241-6.

4. Ghanassia E, Villon L, Thuan Dit Dieudonné JF, Boegner C, Avignon A, Sultan A. Long-term outcome and disability of diabetic patients hospitalized for diabetic foot ulcers: a 6.5-year follow-up study. Diabetes Care. 2008;31(7):1288-92.

5. Zubair M, Malik A, Ahmad J. Incidence, risk factors for amputation among patients with diabetic foot ulcer in a North Indian tertiary care hospital. Foot. (Edinb)2012;22(1):24-30.

6. Köster I, Hauner H, von Ferber L. Heterogeneity of costs of diabetic patients: the Cost of Diabetes Mellitus Study. Dtsch Med Wochenschr. 2006;131(15):804-10.

7. Ragnarson Tennvall G, Apelqvist J. Health-economic consequences of diabetic foot lesions. Clin Infect Dis. 2004;39 Suppl 2:S132-9.

8. Allani R, Saidi O, Mrabet A, Bennelhammami K, Ben Romdhane $\mathrm{H}$. Le diabète type 2 : prévalence et facteurs de risque en Tunisie. Rev Epidémiol Sante Publique. 2012;60(S2):45.

9. Hammami M, Lahiani D, Guemri B, et al. Les infections du pied diabétique : étude de 136 cas. Annales d'Endocrinologie 2015;76(4):552.

10. Ben Moussa M, , Boutiba Ben Boubaker I, et al. Bacteriological and therapeutic profile of diabetic foot infection: a prospective study of 100 patients. Tunis Med 2016;94(2):95-101.

11. Lipsky BA, Berendt AR, Cornia PB, et al. 2012 Infectious Diseases Society of America clinical practice guideline for the diagnosis and treatment of diabetic foot infections. Clin Infect Dis 2012;54(12):e132-73.

12. International Working Group on the Diabetic Foot. International Consensus on the Diabetic Foot and Sup- 
plements, DVD. International Diabetes Federation, Amsterdam, the Netherlands. 2007.

13. Lipsky BA, Berendt AR, Deery HG, et al. Diagnosis and treatment of diabetic foot infections. Clin Infect Dis. 2004;39(7):885-910.

14. Lipsky BA, Medical treatment of diabetic foot infections. Clin Infect Dis. 2004;39: S104-14.

15. Pellizzer G, Strazzabosco M, Presi S, et al. Deep tissue biopsy vs. superficial swab culture monitoring in the microbiological assessment of limb-threatening diabetic foot infection, Diabet. Med. 2001;18:822-27. PubMed

16. Richard JL, Lavigne JP, Got I, et al. Management of patients hospitalized for diabetic foot infection: Results of the French OPIDIA study. Diabetes Metab. 2011;37(3):208-15.

17. Tascini C, Piaggesi A, Tagliaferri E, et al. Microbiology at first visit of moderate-to-severe diabetic foot infection with antimicrobial activity and a survey of quinolonemonotherapy. Diabetes Res Clin Pract. 2011;94(1):133-9.

18. Akhi MT, Ghotaslou R, Asgharzadeh M, et al. Bacterial etiology and antibiotic susceptibility pattern of diabetic foot infections in Tabriz, Iran. GMS Hyg Infect Control. 2015;10:Doc02.

19. Perim MC, Borges Jda C, Celeste SR, et al. Aerobic bacterial profile and antibiotic resistance in patients with diabetic foot infections. Rev Soc Bras Med Trop. 2015;48(5):546-54.

20. Mendes JJ, Marques-Costa A, Vilela C, et al. Clinical and bacteriological survey of diabetic foot infections in Lisbon. Diabetes Res Clin Pract. 2012;95(1):153-61.
21. Al Benwan K, Al Mulla A, Rotimi VO. A study of the microbiology of diabetic foot infections in a teaching hospital in Kuwait. J Infect Public Health. 2012;5(1):1-8.

22. Sekhar S, Vyas N, Unnikrishnan M, Rodrigues G, Mukhopadhyay C. Antimicrobial susceptibility pattern in diabetic foot ulcer: a pilot study. Ann Med Health Sci Res. 2014;4(5):742-5.

23. Hatipoglu M, Mutluoglu M, Uzun G, Karabacak E, Turhan V, Lipsky BA. The microbiologic profile of diabetic foot infections in Turkey: a 20 -year systematic review: diabetic foot infections in Turkey. Eur J Clin Microbiol Infect Dis. 2014;33(6):871-8.

24. Charles PG, Uçkay I, Kressmann B, Emonet S, Lipsky BA. The role of anaerobes in diabetic foot infections. $A n$ aerobe. 2015;34:8-13.

25. Lipsky BA, Tabak YP, Johannes RS, Vo L, Hyde L, Weigelt JA. Skin and soft tissue infections in hospitalised patients with diabetes: culture isolates and risk factors associated with mortality, length of stay and cost. Diabetologia. 2010;53(5):914-23.

26. Martínez-Gómez Dde A, Ramírez-Almagro C, Campillo-Soto A, Morales-Cuenca G, Pagán-Ortiz J, Aguayo-Albasini JL. Diabetic foot infections. Prevalence and antibiotic sensitivity of the causative microorganisms. Enferm Infecc Microbiol Clin. 2009;27(6):317-21.

27. Huang Y, Cao Y, Zou M, et al. A Comparison of Tissue versus Swab Culturing of Infected Diabetic Foot Wounds. Int J Endocrinol. 2016;2016:8198714.

28. Slater RA, Lazarovitch T, Boldur I, et al.Swab cultures accurately identify bacterial pathogens in diabetic foot wounds not involving bone. Diabet Med. 2004;21(7):705-9. 